Www.jmscr.igmpublication.org

Index Copernicus Value: 79.54

ISSN (e)-2347-176x ISSN (p) 2455-0450

crossref DOI: https://dx.doi.org/10.18535/jmscr/v7i4.184

Journal Of Medical Science And Clinical Research

IGM Publication

An Official Publication of IGM Publication

\title{
Spectrum of Ophthalmic Manifestations of Dengue: Our Experience in a Tertiary Care Centre
}

\author{
Authors
}

\section{Srikant Kumar Dhar ${ }^{1}$, Swati Samant ${ }^{2}$, Suchismita Mishra ${ }^{3}$, Debasmita Tripathy ${ }^{4}$, Rishit D. Shah ${ }^{5}$, Ram Chandra Prasad \\ ${ }^{1}$ Professor, PG Department of Medicine, IMS and SUM hospital, Siksha "O” Anusandhan, K8, \\ Kalinganagar, Bhubaneswar-751003, Odisha, India}

${ }^{2}$ Associate Professor, PG Department of Ophthalmology, IMS and SUM hospital, Siksha "O” Anusandhan University, K8, Kalinganagar,Bhubaneswar-751003, Odisha, India

${ }^{3}$ Assistant Professor, PG Department of Ophthalmology, IMS and SUM hospital, Siksha "O" Anusandhan

University, K8, Kalinganagar,Bhubaneswar-751003, Odisha, India

${ }^{4}$ Assistant Professor, PG Department of Medicine, IMS and SUM hospital, Siksha "O” Anusandhan

University, K8, Kalinganagar,Bhubaneswar-751003, Odisha, India

${ }^{5}$ Junior Resident, PG Department of Ophthalmology, IMS and SUM hospital, Siksha "O” Anusandhan

University, K8, Kalinganagar,Bhubaneswar-751003, Odisha, India

${ }^{6}$ Junior Resident, PG Department of Medicine, IMS and SUM hospital, Siksha "O” Anusandhan University, K8, Kalinganagar,Bhubaneswar-751003, Odisha, India

*Corresponding Author

Suchismita Mishra

Assistant Professor, PG Department of Ophthalmology, IMS and SUM hospital, Siksha "O" Anusandhan University, K8, Kalinganagar,Bhubaneswar-751003, Odisha, India

Email: drsuchismitamkcg@gmail.com

\section{Abstract}

Background: Dengue is a multisystem disease by a viral infection affecting all organs. Ophthalmic manifestation are not uncommon but mostly under observed. we evaluated cases of dengue fever with different ophthalmic manifestations. Introduction: Dengue is a vector borne disease by four different serotypes of dengue virus transmitted by bite of female Aedes mosquito. It is an acute febrile illness characterised by myalgia, joint pain, gastrointestinal manifestations. Complications like dengue hemorrhagic fever (DHF) and Dengue shock syndrome (DSS), Extended Dengue Syndrome (EDS) may be fatal for patients. Ophthalmic manifestations like conjuctival chemosis and bleeding manifestation like retnal hemorrage associated with low platelet count. We determine different clinical spectrum of of ophthalmic manifestations and correlation to platelet level.

Materials and Methods: This study conducted over one year from August 2017 to September 2018 comprising of 110 dengue patients in IMS \& SUM Hospital. Complete ocular examination was carried out to establish ocular manifestations.

Result: Out of 110 hospitalised patients (Age >18 years) 85 were males $(77.27 \%)$ and 25 were females $(22.72 \%)$. Mean age of presentation was 38.53 years (18-65years).Ocular findings were present in 47 patients $(42.72 \%)$, Subconjunctival haemorrhage (SCH) was the commonest ocular finding 29 patients $(61.72 \%)$.Posterior segments finding was present in 11 patients (10\%),7 patients(6.36\% )had superficial retinal haemorrhage. Thrombocytopenia was noted in 47 patients (43.03\%) of which 34 patients (72.34\%) had ocular findings. All patients of DSS and EDS had ocular findings, $70 \%$ cases of DHF and $37.5 \%$ cases of DF had ocular manifestations. Raised haematocrit is also 
associated with ocular manifestations.

Conclusion: The incidence of dengue fever is increasing so also ocular complications, hence all patients with dengue should be evaluated to prevent any sight-threatening complications.

Keywords: Dengue, Subconjunctival haemorrhage, Platelets, Packed cell volume.

\section{Introduction}

Dengue is a vector borne disease. Its virus, is a member of the genus Flavivirus of the family Flaviviridae, that includes four different serotypes (DEN-1, DEN-2, DEN-3, and DEN-4). ${ }^{1,2}$ Dengue is a major global public health problem in the tropic and subtropic nations. Worldwide there is an upsurge of dengue infection between 1960 and 2010, due to increased population growth rate, global warming, unplanned urbanization, inefficient mosquito control, frequent air travel, and lack of health care facilities. ${ }^{3,45}$ Nearly3.97 billion people from 128 countries are at risk of infection. ${ }^{6-7}$ WHO region of western Pacific and Sourthen Asia (SEA) represent approximately 75 $\%$ of global burden of dengue. ${ }^{8}$ The first reported case of dengue like illness in India was in Madras in 1780, the first virologically proved epidemic of Dengue fever(DF) in India occurred in Calcutta and Eastern Coast of India in 1963-1964. ${ }^{9}$ Since mid 1990s,epidemics of dengue in India have become frequent, especially in urban zones, and have quickly spread to regions, such as Arunachal Pradesh, Mizoram and Odisha. ${ }^{10}$ In early 2000s, dengue was endemic in a few southern and northern states, recently it had spread to a number of new states and union territories. ${ }^{10}$ It has also spread from urban to rural regions. ${ }^{11}$

Dengue is transmitted by bite of female. Aedes mosquito, Ades aegypti and Aedes albopictus main vectors in India $^{12}$. Trasmission usually occurs in rainy season. Etiology for dengue viral infections are viral replication, primarily in macrophages $^{13}$ and immunological and chemicalmediated mechanism induced by host-viral interaction. Humoral, cellular, and innate immunity of host are implicated in the progression of the illness. Dengue is clinically characterized by acute onset of biphasic, high-grade fever lasting for 3 days to 1 week, associated with symptoms of malaise, vomiting, cough, headache (retro-orbital), muscle ache, joint pain, vomiting and stomach-ache. ${ }^{14-15}$ Of patients with DF, 50$82 \%$ report with a peculiar cutaneous rash. ${ }^{16-17}$ Severe clinical presentation during the infection course does not correlate with a high viral load. ${ }^{13}$ Dengue infection is diagnosed clinically but confirmed by laboratory test. Virus segregation in cell cultures, nucleic acid demonstration by polymerase chain reaction (PCR), and serological detection of viral antigens (such as NS1) or particular antibodies are the preferred microbiological assays. ${ }^{5}$ During early phase of infections (febrile period), dengue PCR is performed. After febrile illness dengue IgG and Ig $\mathrm{M}$ is preferred tests.

Dengue is a self limiting infection mostly. Oral facial features are less frequently seen in dengue virus infection but are slightly more commonly associated with dengue haemorragic fever (DHF). Chadwick et al. reported higher cases involving the mucosa with scleral injection $(90 \%) .{ }^{18}$ Clinical signs in ophthalmology ranges from simple conjunctival congestion to vision threatening complications. According to intergovernmental Panel on Climate Change, the global average temperature has increased by $0.6^{0} \mathrm{C}$ over last 35 years, and variation of perception has increased. ${ }^{19}$ Temperature and humidity are important clinical factors in growth of mosquito population and disease transmission dynamics. ${ }^{20}$ Due to warm temperature in Odisha there is increase surge of dengue infection every year, which made to clinch our attention towards study on ocular manifestations of dengue and to identify any significant laboratory parameters associations with ophthalmological findings.

\section{Materials and Methods}

This study was a prospective, observational study conducted in department of Ophthalmology comprising of 110patients suffering from dengue 
selected from Indoor of Department of Medicine of IMS and SUM Hospital, a tertiary care hospital, Bhubaneswar, during the period from August 2018-September 2018.During this period ,several parts of Odisha experienced an unexpected epidemic of dengue infection.

Patients who had fever and who were found to be positive for NS1 antigen (Micro ELISA, J. Mitra) and dengue Ig M (antibody) were enrolled. Total of 110 patients (age>18 years) were enrolled during the outbreak of disease. Adetail clinical history, systemic examination routine haematological examination i.e haemoglobin (Hb), total leukocyte count (TLC), platelet count (PC), malarial antigen, slide test for malaria parasite, IgM antibodies and Widal test for typhoid was performed. Complete ocular examination like visual acquity, slit lamp examination, intraocular pressure by gold man application tonometery and indirect ophthalmoscopy was carried out. Patients who were suffering from diabetes, hypertension and other correlated disease were excluded from our study. All subjects were classified according to WHO guideline as shown in Table 1.Thrombocypopenia was taken as platelet count less than $1 \mathrm{lakh} / \mathrm{mm}^{3}$ and leuopenia as white blood cells $(\mathrm{WBC})<5000$ cells $/ \mathrm{mm}^{3}$

Data were entered and analysed in SPSS version 12 statistical software.

\section{Results}

A total of 110 hospitalised patients (Age >18 years) diagnosed as dengue were enrolled in our study out of which 85 patients were males (77.27\%) and 25 patients were females (22.72\%). Mean age of presentation was 38.53 years (1865years). Maximum number of case was found in age group 30-40 years. Mean time of presentation was 7 days (4-14 days).Median duration of stay in hospital was 7 days. Patient mainly belong to low socioeconomic status with predominate labours and working class. $61 \%$ patients were aware that dengue spread by mosquito bite.
In our series, all cases (100\%) presented with fever, myalgia (82.3\%), headache (60.22 \%) others clinical features are nausea, pain abdomen, loose motion, puritus etc. None of our patient have visual complains. Retro-orbital pain was noted in 9 patients $(8.18 \%)$. Platelets count varied widely in our study. The lowest being $16000 / \mu \mathrm{L}$. Thrombocytopenia was noted in 47 patients (47.72\%). Leucopenia was noted in 63(57.27\%). Neurological manifestations found in 2 cases. Out of $110,54.54 \%$ patients were NS1 positive, IgM positive in $13.04 \%$ of NS1 patients, only Ig M positive was noted in $30.90 \%$, IgM and IgG positive in $4.5 \%$ of case which indicated secondary cases. Relationship of antigen antibody pattern to clinical manifestations: in our series, all patient having IgG and IgM have eye manifestations.

Ocular findings were present in 47 patients (42.72\%) (Table-3). Periorbital lid edema (Fig1), conjuctival congestion (Fig2) and periorbital echymosis (Fig 3) are detected in few cases. Subconjunctival haemorrhage ( $\mathrm{SCH}$ ) was the most commonest ocular finding ( Fig 4a,b,c,d), noted in 29 patients (61.72\%);60\% patients have bilateral $\mathrm{SCH}$. Petichae type of SCH was noted in 23 patients $(79.31 \%)$ and 6 patients $(20.68 \%)$ have diffuse haemorrhage.

Posterior segments finding was present in 11 patients(10\%).7 patients $(6.36 \%)$ had superficial retinal haemorrhage, 1 patient $(0.9 \%)$ had hard exudates, 2 patients (1.8\%)had soft exudates and 1 patient $(0.9 \%)$ had bilateral disc edema. The superficial haemorrhage were scattered in fundus and was not found in macula (Fig.5).

All patients of DSS and EDS had ocular findings, $70 \%$ cases of DHF and $37.5 \%$ cases of DF had ocular manifestations (Table-4).

In laboratory parameter thrombocytopenia was noted in 47 patients (43.03\%) of which 34 patients (72.34\%) had ocular findings. Leucopenia was present in 63 patients $(57.27 \%)$ of which 14 patients $(22.22 \%)$ had ocular finding which is statically not significant (p). Raised haematocrit is also associated with ocular manifestations .Others 
parametes like prolong prothrombin (PT) and partial prothrombin time (PTT) correlation could not be established with ocular haemorrhage in our study as not done in all cases.

\section{Age distribution of patients}

Age distribution of 110 patients is depicted in Table 1.Out of which.85 males and 25 were females

Table 1: Age at presentation

\begin{tabular}{|l|c|c|}
\hline $\begin{array}{l}\text { Age at } \\
\text { presentation }\end{array}$ & $\begin{array}{c}\text { Number of } \\
\text { patients }\end{array}$ & Percentage \\
\hline $18-20$ & 7 & $6.36 \%$ \\
\hline $20-30$ & 23 & $20.90 \%$ \\
\hline $30-40$ & 35 & $31.81 \%$ \\
\hline $40-50$ & 27 & $24.54 \%$ \\
\hline $50-60$ & 12 & $10.90 \%$ \\
\hline$>60$ & 6 & $5.45 \%$ \\
\hline
\end{tabular}

Table-2: Antigenic/ Antibody presentations of Dengue Cases

\begin{tabular}{|l|c|}
\hline & \\
\hline NS1 Antigen & 60 \\
\hline IgM Antibody & 34 \\
\hline NS1 Antigen +IgM Antibody & 9 \\
\hline IgM Antibody+ IgG Antibody & 5 \\
\hline NS1 Antigen +IgM Antibody+IgG antibody & 2 \\
\hline
\end{tabular}

Table -3: Ocular Manifestations in patients with dengue

\begin{tabular}{|l|c|c|}
\hline Ocular finding & $\begin{array}{c}\text { Number of } \\
\text { patients }\end{array}$ & $\begin{array}{c}\% \text { of total } \\
\mathrm{n}=110\end{array}$ \\
\hline Anterior segment findings & 36 & $32.72 \%$ \\
\hline Subconjunctival haemorrhage & 29 & $26.36 \%$ \\
\hline Chemosis & 6 & $5.45 \%$ \\
\hline Lid edema & 1 & $0.9 \%$ \\
\hline Posterior segment finding & 11 & $10 \%$ \\
\hline Retinal haemorrhage & 7 & $6.36 \%$ \\
\hline Hard exudates & 1 & $0.9 \%$ \\
\hline Soft exudates & 2 & $1.8 \%$ \\
\hline Disc edema & 1 & $0.9 \%$ \\
\hline
\end{tabular}

Table 4: Ocular manifestations in different dengue patients

\begin{tabular}{|l|l|c|c|c|c|}
\hline & DF & DHF & DSS & EDS & Total \\
\hline $\begin{array}{l}\text { With ocular } \\
\text { findings }\end{array}$ & $\begin{array}{l}36(37 . \\
5 \%)\end{array}$ & $7(70 \%)$ & $\begin{array}{c}2(100 \% \\
)\end{array}$ & $\begin{array}{c}2(10 \\
0 \%)\end{array}$ & $\begin{array}{c}47 \\
(42.72 \%)\end{array}$ \\
\hline $\begin{array}{l}\text { Without } \\
\text { ocular } \\
\text { findings }\end{array}$ & $\begin{array}{l}60(62 . \\
5 \%)\end{array}$ & $3(30 \%)$ & $0(0 \%)$ & $0(0 \%$ & $\begin{array}{c}63 \\
(57.27 \%)\end{array}$ \\
\hline Total Patients & 96 & 10 & 2 & 2 & $\begin{array}{c}110 \\
(100 \%)\end{array}$ \\
\hline
\end{tabular}

Note: DF, Dengue Fever; DHF, Dengue Haemorragic fever; DSS, Dengue Shock syndrome; EDS, Expanded dengue syndrome
Table -5: Laboratory finding and association with ocular manifestations

\begin{tabular}{|l|c|c|}
\hline $\begin{array}{l}\text { Laboratory } \\
\text { parameter }\end{array}$ & $\begin{array}{c}\text { With ocular } \\
\text { Finding }\end{array}$ & $\begin{array}{c}\text { Without } \\
\text { ocular finding }\end{array}$ \\
\hline Platelets count & & \\
\hline$>100000 / \mu 1$ & $13(20.63 \%)$ & 50 \\
\hline $50-100000 / \mu 1$ & $14(60.3 \%)$ & 9 \\
\hline $20-50000 / \mu 1$ & $15(83.3 \%)$ & 3 \\
\hline$<20000 / \mu \mathrm{l}$ & $5(83.3 \%)$ & 1 \\
\hline Total & & \\
\hline WBC count & & 33 \\
\hline$\geq 4000 / \mathrm{ml}$ & 14 & 49 \\
\hline$\leq 4000 / \mathrm{ml}$ & 14 & 7 \\
\hline PCV & 0 & 8 \\
\hline $20-25$ & 0 & 16 \\
\hline $26-30$ & 5 & 16 \\
\hline $31-35$ & 14 & 12 \\
\hline $36-40$ & 18 & 4 \\
\hline $41-45$ & 8 & 0 \\
\hline $46-50$ & 2 & \\
\hline$>50$ & & Packedl \\
\hline & & \\
\hline
\end{tabular}

Note: WBC, white blood cells; PCV, Packed cell volume; PTT, Partial thromboplastin time; PT, Prothrombin time. PT and PTT were carried in 60 patients only

\section{Discussion}

The incidence, clinical manifestation and geographical distribution of dengue have increased due to increase in global temperature and population growth rate, unplanned urbanization, inefficient mosquito control, frequent air travel, and lack of health care facilities. ${ }^{3,4,5}$

Dengue affects human of all age group. In our series the mean age of presentation is 38.53 years (30-40 years) which is similar to other studies ${ }^{22,22}$ with a male preponderance. ${ }^{23,24}$

Dengue has diverse of clinical manifestations starting from simple fever to severe encephalopathy. In our series all patient presented with fever $(100 \%)$, followed by myalgia (84\%). Headache is also one of presentation $60.22 \%$ but retro-orbital pain which is a classical feature of dengue was seen in $8.6 \%$ of cases which is much less other authors ${ }^{25,26}$ more than Kapoor at al. ${ }^{23}$ 


\section{JMSCR Vol||07||Issue||04||Page 1120-1128||April}

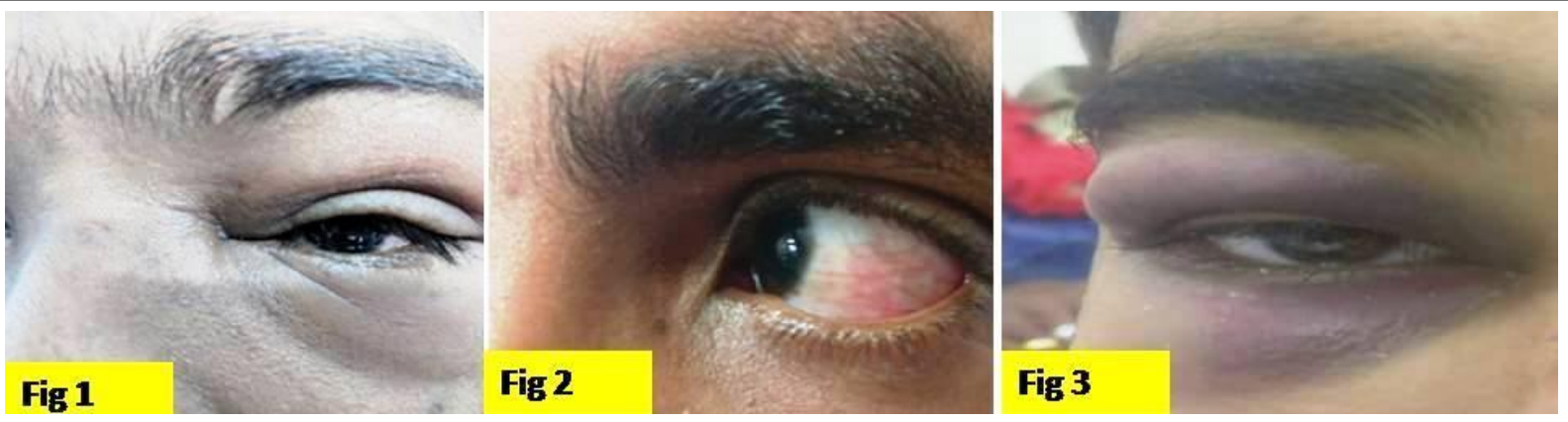

Figure 1: Periorbital Edema in Dengue

Figure 2: Conjuctival Congestion

Figure 3: Periorbital Echimosis
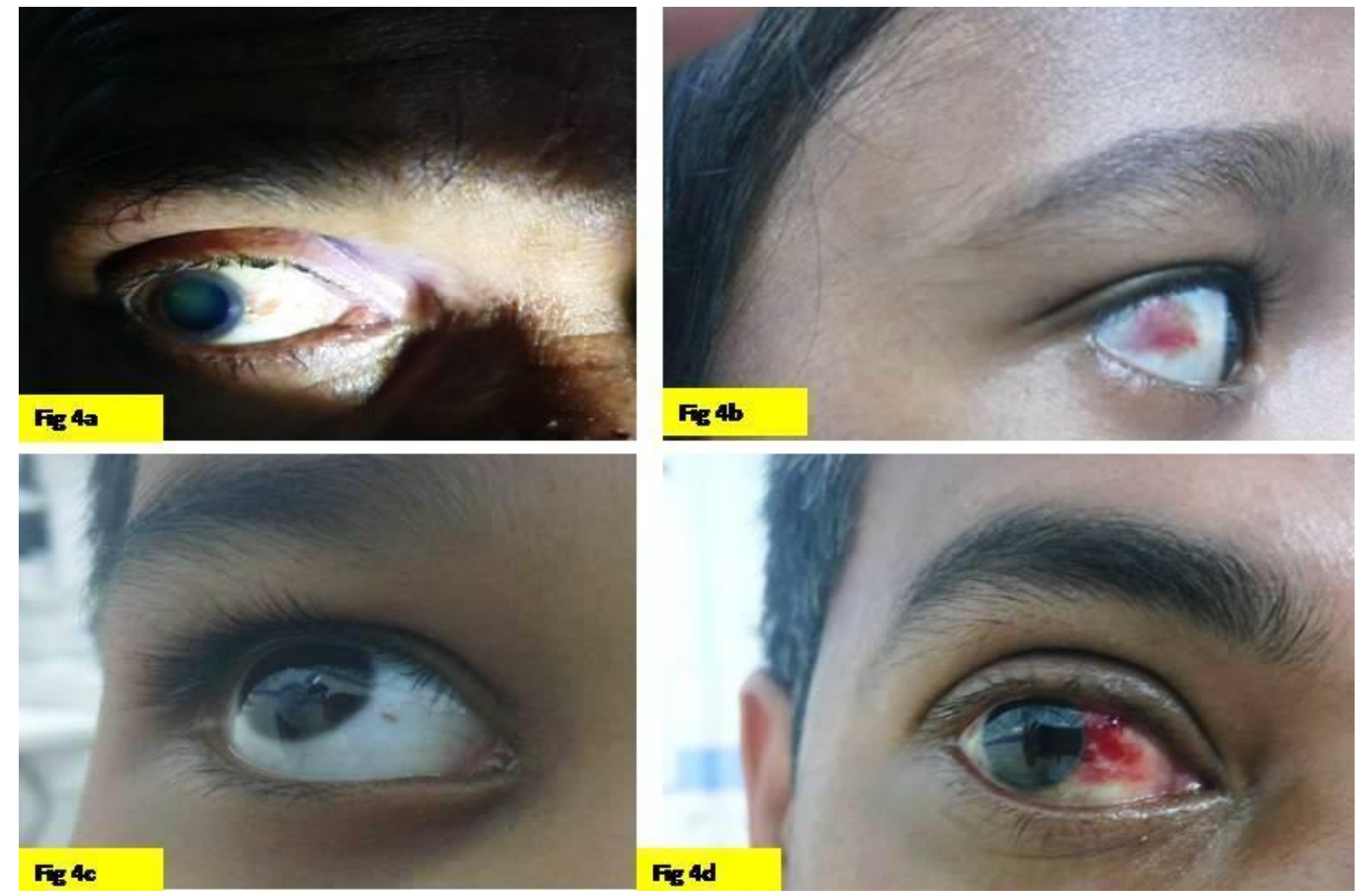

Figure 4 (a,b,c,d)- Sub Conjuctival Hemorrage

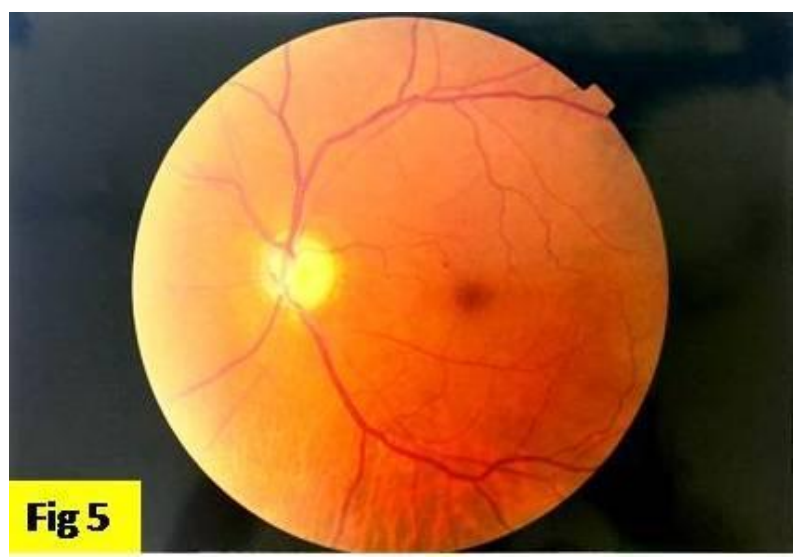

Figure 5: Dot-Blot Hemorrage 
Ocular manifestations of dengue have received less attention in published literature in past. There are published report on dengue, primary presented on these reports was visual complains but in our scenario none of our patients had any type of visual complains. Anterior segment manifestations has been reported in form of subconjunctival haemorrhage $(\mathrm{SCH})$, anterior uveities, ptosis, periorbital echemosis $\operatorname{etc}^{23,24,27}$ and in posterior segment reports have been published presentationin form of macular edema, vitreous haemorrhage, vascular occlusion, vasculities with retinal haemorrhage and cotton wool spots. $^{28,29,30,31,32}$ Very few reports are there who published both anterior and posterior segments finding with its correlation with different blood parameters. $^{23}$

In our series $42.75 \%$ of patient had ocular manifestation which is almost similar to that of Kapoor et al. ${ }^{23}$ Anterior segment finding was seen in $32.72 \%$ of which $\mathrm{SCH}$ was commonest clinical presentations $(26.36 \%)$ which is similar to studies by Sujatha and Hussian et $\mathrm{al}^{33,24}$; however ,in contrast to these studies one patient presented with a atypical presentation ie bilateral lid edema with echemosis. Similar presentation was reported by Vinod at el. ${ }^{27}$

Only $10 \%$ cases have posterior segment finding which is almost similar to Kapoor at el. ${ }^{23}$ Posterior segment finding inform of retinal haemorrhage, cotton wool spot, hardexudates and disc edema. We did not find any maculopathy patient which explained the fact that there was no visual complains in our patients. None of the patients in our series had anterior uveities, protosis, retrobulbar haemorrage, optic neuritis and retinal vasculities. In our study, ocular finding varied from anterior and posterior segment more findings in anterior segmrent as the study done by Sujatha et al but in contrast to Lim et al which have only posterior segments finding. ${ }^{30,33}$

There are four different serotype in dengue, variation in virus strain within and between different serotype influence disease severity. ${ }^{34}$ In our series we encountered mostly dengue fever patients of which $37.5 \%$ have ocular manifestations. In our series all patients of EDSS and DSS had ocular manifestations but we cannot take inference, that all persons of EDSS and DSS will have ocular manifestations, as we encountered very few cases in this group in our series. EDSS and DSS have more ocular manifestations as compared to other groups as they have increased haematocrit value with increase plasma leakage.

The pathophysiology of dengue infections is complex and not completely understood. Various manifestations of dengue is due to direct virus invasion or complex immune mechanism comprise of complement system pathway and NK cells. Complements activation due to immune activation and cytokine production are involved in mechanism of plasma leakage. Various cytokines that may induces plasma leakage are interlulin (IL)-2, interferon $\mathrm{g}$, tumornecrosis factor (TNF) $\alpha$, IL-6,IL-8 and IL10. ${ }^{35-36}$ Ocular finding in our patients like $\mathrm{SCH}$, hard exudates and retina haemorrhage could be explained by increased capillary permeability, plasma leakage and haemorragic diathesis due to endothelial dysfunction. The pathogenesis of cotton wool spot in dengue may be due to occlusion of pre capillary arterioles in nerve fibre layer by immune complex deposits. Lim at el suspected there is possibility of production of specific autoantibody agnaist retina, retinal pigment epithelium or chroid. ${ }^{30}$ The exact mechanisms of various ocular manifestations in dengue arestill unclear.

Thrombocytopenia is a consistent finding in dengue infection, prolong plasma prothombin time (PTT) and reduced fibrinogen concentration are other abnormal haemostatic indices evident and these correlates with severity of plasma leakage. ${ }^{37}$ According to Wills et al these abnormality correlates with timing and severity of plasma leakage rather than clinical manifestations. ${ }^{38}$ Similarly Gomber et al reported no significant association between thrombocytopenia and haemorragic manifestations. ${ }^{39}$ Thrombocytopenia and abnormal coagulation 
profiles have been reported to have predictive value for systemic bleeds. ${ }^{24}$ There are few reports published with ocular manifestations and abnormal laboratory parameters. In our study Correlations with other parameters, like leucopenia and prolong PT, PTT could not be established.

One dengue serotype elicits immunity to that serotype but does not provide cross -protection immunity to other serotypes. Recovery from infections with one serotype provides lifelong immunity against that serotype, but partial immunity against other serotypes 4,20 . Sequential infections with other serotype increases risk of serious systemic disease like DHF, DSS Subsequent infections with different serotype results in binding new virus to cross react with non neutralising antibody from previous infection facilitating uptake by mononuclear phagocyte and thus enabling amplified viral replication, which drives immuopathogenic cascade and thus increased cytokine responses. ${ }^{37}$ Thus this may explain the fact that the ocular manifestations are more in patients who have reinfections. (Table-2).

Ocular manifestations in dengue is usually self limiting. ${ }^{24}$ According Haritoglou et al most finding resolve without any specific treatments but visual recover may be prolong or permanently impaired in patients with severe maculopathy. ${ }^{24}$ Our study is a- and non interventional study, so we have not re-examined the patients and so cannot described time taken to resolve which is our limitation.

\section{Conclusion}

There is increase in epidemicity of dengue infections and thus ophthalmic manifestations are expected to rise. The treating physician should be aware of various ophthalmic manifestations in dengue. They should promptly refer patients who have detoriated blood parameters, patients complaining of blurring of vision, dengue reinfection cases and patients of DHF, DSS and EDS to ophthalmologist for earlier evaluation. Ophthalmologist should also be aware of various ocular manifestations, as early referral for supportive therapy can decrease mortality by appropriate treatment. Patients who have marked thrombocytopenia and dear ranged hamatocrit are more predisposed to ocular manifestations may it be simple $\mathrm{SCH}$ or macular haemorrhage which can impair vision.

\section{Reference}

1. Halstead SB. Pathogenesis of dengue: Challenges to molecular biology. Science. 1988;239:476-81. [PubMed]

2. Kurane I. Dengue hemorrhagic fever with special emphasis on immunopathogenesis. Comp Immunol Microbiol Infect Dis. 2007;30:329-40. [PubMed]

3. Gubler DJ. Dengue and dengue Hemorrhagic fever. Clin Microbiol Rev. 1998;11:480-96. [PMC free article PubMed

4. New ed. Geneva, Switzerland: World Health Organization; 2009. World Health Organization (WHO). Dengue- Guidelines for Diagnosis, Treatment, Prevention and Control.

5. Guzman MG, Halstead SB, Artsob $\mathrm{H}$, Buchy P, Farrar J, Gubler DJ, et al. Dengue: A continuing global threat. Nat Rev Microbiol. 2010;8(Suppl):S7-16. [PMC free article][PubMed]

6. Bhatt S, Gething PW, Brady OJ et al. The global distribution and burden of dengue. Nature 2013; 496: 504-507. [PMC free article][PubMed]

7. Brady OJ, Gething PW, Bhatt $\mathrm{S}$ et al. Refining the global spatial limits of dengue virus transmission by evidencebased consensus. PLoS Negl Trop Dis 2012; 6: e1760. [PMC free article] [PubMed

8. Aguiar M, Rocha F, Pessanha JEM et al. Carnival or football, is there a real risk for acquiring dengue fever in Brazil during holidays seasons? Sci Rep 2015; 5: 8462. [PMC free article][PubMed 
9. Gupta N, Srivastava S, Jain A, Chaturvedi UC. Dengue in India.Indian J Med Res. 2012;136:373-90. [PMC free article] [PubMed]

10. Chakravarti A, Arora R, Luxemburger C. Fifty years of dengue in India. Trans R Soc Trop Med Hyg 2012; 106: 273-282. [PubMed]

11. Arunachalam N, Murty US, Kabilan L et al. Studies on dengue in rural areas of Kurnool District, Andhra Pradesh, India. J Am Mosq Control Assoc 2004; 20: 87-90. [PubMed[

12. Gubler DJ. Dengue and dengue hemorrhagic fever. Clin Microbiol Rev 1998; 11: 480-496.

13. Whitehorn J, Simmons CP. The pathogenesis of dengue. Vaccine. 2011;29:7221-8. [PubMed]

14. Dhar srikant.,A Study on the Clinicopathological Profile and Outcome of a Dengue Epidemic in Western Odisha. International Journal of Medical Science and Innovative Research. 2017;2(4):1320.

15. Narayanan M, Aravind MA, Thilothammal N, Prema R, Sargunam CS, Ramamurty N. Dengue fever epidemic in Chennai-a study of clinical profile and outcome. Indian Pediatr. 2002;39:1027-33. [PubMed]

16. Waterman SH, Gubler DJ. Dengue fever. Clin Dermatol. 1989;7:117-22. [PubMed]

17. Itoda I, Masuda G, Suganuma A, Imamura A, Ajisawa A, Yamada K, et al. Clinical features of 62 imported cases of dengue fever in Japan. Am J Trop Med Hyg. 2006;75:470-4. [PubMed]

18. Chadwick D, Arch B, Wilder-Smith A, Paton N. Distinguishing dengue fever from other infections on the basis of simple clinical and laboratory features: Application of logistic regression analysis. J Clin Virol. 2006;35:147-53.

19. IPCC.Climate Change 2013: The Physical Science Basis. InStocker TF, Qin D,
Plattner GK et aleds. Contribution of Working Group I to the Fifth Assessment Report of the Intergovernmental Panel on Climate Change. Cambridge University Press: Cambridge, UK and New York, NY, USA. 2013, 1535.

20. Patz JA, Martens WJ, Focks DA et al. Dengue fever epidemic potential as projected by general circulation models of global climate change. Environ Health Perspect 1998; 106: 147-153

21. Haritoglou C, Scholz F, Bialasiewicz A, Klauss V. [Ocular manifestation in dengue fever]. Ophthalmologe. 2000 Jun; 97(6):433-6. German. PubMed PMID: 10916388 .

22. Yip VC, Sanjay S, Koh YT. Ophthalmic complications of dengue Fever: asystematic review. Ophthalmol Ther. 2012 Dec;1(1):2. doi:10.1007/s40123-0120002-z. Epub 2012 Aug 23. PubMed PMID: 25135582; PubMed

23. Kapoor HK, Bhai S, John M, Xavier J. Ocular manifestations of dengue fever in an East Indian epidemic. Can J Ophthalmol. 2006 Dec;41(6):741-6. PubMed PMID: 17224957.

24. Hussain I, Afzal F, Shabbir A, Adil A, Zahid A,Tayyib M. Ophthalmic manifestation of dengue fever. Ophthalmol Updte 2012:10:93-6

25. Sharp TW, Wallace MR, Hayes CG, Sanchez JL, DeFraites RF, Arthur RR, Thornton SA, Batchelor RA, Rozmajzl PJ, Hanson RK, et al. Dengue fever in U.S. troops during Operation Restore Hope, Somalia, 1992-1993. Am J Trop Med Hyg. 1995 Jul;53(1):89-94. PubMed PMID: 7625541.

26. Narayanan M, Aravind MA, Thilothammal N, Prema R, Sargunam CS, Ramamurty N. Dengue fever epidemic in Chennai--a study of clinical profile and outcome. Indian Pediatr. 2002 Nov;39(11):1027-33. PubMed PMID: 12466573. 
27. Kumar V, Ghosh B, Raina UK, Goel N. Bilateral periorbital ecchymosis in a casewith dengue fever. Indian $\mathbf{J}$ Ophthalmol. 2009 May-Jun;57(3):242-3. doi:10.4103/0301-4738.49407.

28. Chan DP, Teoh SC, Tan CS, Nah GK, Rajagopalan R, Prabhakaragupta MK, Chee CK, Lim TH, Goh KY; Eye Institute Dengue-Related Ophthalmic Complications Workgroup. Ophthalmic complications of dengue. Emerg Infect Dis. 2006 Feb;12(2):285-9.

29. Sanjay S, Wagle AM, Au Eong KG. Optic neuropathy associated with dengue fever.Eye (Lond). 2008 May;22(5):722-4.

30. Lim WK,Mathur R,Koh A,Yeoh R,Chee SP. Ocular manifestrations of dengue fever. Ophthalmology 2004;111:2057-64.

31. Sanjay S, Au Eong KG. Bilateral vitreous haemorrhage associated with dengue fever. Eye (Lond). 2007 Jan;21(1):144-5.

32. Cruz-Villegas V, Berrocal AM, Davis JL. Bilateral choroidal effusions associated with dengue fever. Retina. 2003 Aug;23(4):576-8.

33. Sujatha R, Nousheen S, Nazlin A, Prakash S. Ocular manifestations of dengue fever. Int J Med Sci Public Health 2015;4:690693

34. Haritoglou C, Dotse SD, Rudolph G, Stephan CM, Thurau SR, Klauss V. A tourist with dengue fever and visual loss. Lancet. 2002 Oct 5;360(9339):1070.

35. I.Kurane and E.A.Ennis,"Cytokines in dengue virus infection : role of cytokines in pathogenesis of dengue haemorrhagic fever," Seminars in Virology,vol 5,no.6,pp.443-448,1994.

36. S. Green, S. Pichyangkul, D.W. Vaughn et al.'Early CD69 expression on peripheral blood lymphocytes from children with dengue haemorragic fever", Journal of infectious isease,vol.180,no.5,pp.14291435,1999 .
37. S. Halstead, "Pathophysiology and pathogenesis of dengue haemorrhagic fever." in Monograph on Dengue/Dengue Haemorrhagic Fever, P.T Hongcharoen, Ed., Regional Publication,SEARO no.22,pp.80-103,WHO,1993.

38. D.M. Morens," Antibody-dependent enhancement of infection and the pathogenesis of viral disease, "Clinical Infections Disease,vol.19,pp.500-512,1994

39. B.A. Wills, N.M.Dung, H.T.Loan et al." Comparision of three fluid solutions for resuscitation in dengue shock syndrome", The New England Journal of Medicine, vol.353,no.,pp.877-889,2005.

40. Gomber S, Ramachandran VG, Kumar S,et al. Haematological observations and diagnostic markers in dengue haemorrhagic fever-a reappraisal. Indian Pediatr 2001;38:477-81. 